\title{
Perde-se a capital, ganha-se um jornal: a criação da Tribuna de Petrópolis e o resgate do poder simbólico e político regional ${ }^{1}$
}

\author{
Verônica Soares da $\operatorname{COSTA}^{2}$
}

\begin{abstract}
Resumo:
Fundada em 1902 e em circulação até os dias atuais, a Tribuna de Petrópolis acumula mais de um século de publicação na cidade serrana de Petrópolis, no Estado do Rio de Janeiro. No início do século XX, o jornal foi importante instrumento de (re)posicionamento político do chamado Grupo de Petrópolis, união de políticos que lutavam pelo resgate do poder após a perda da capital do Estado para a cidade de Niterói. Os conflitos políticos e a constante tensão se faziam presentes nas páginas do periódico em seus primeiros anos de circulação. Em suas páginas, o esforço pelo resgate de uma Era de Ouro e as tentativas de recuperação da chancela de capital refletiam os interesses e os poderes por trás da tinta e do papel. O estudo se desenvolveu a partir de pesquisa bibliográfica sobre o contexto histórico-político e pesquisa exploratória nos exemplares da Tribuna de Petrópolis localizados no acervo do Arquivo Histórico da Biblioteca Municipal Gabriela Mistral, em Petrópolis, RJ.

Palavras-chave:

História da mídia regional. Tribuna de Petrópolis. Mídia e poder.

\section{You lose the capital, you get a newspaper: Tribuna de Petropolis and the redemption of the symbolic and political regional power}

\begin{abstract}
:
Founded in 1902 and still in circulation until the present day, Tribuna de Petrópolis is a local newspaper published in Petrópolis, in the state of Rio de Janeiro, Brazil. In the early years of the 20th century, the newspaper was an important instrument for the political (re)position of the so-called Petrópolis Group, a group of politicians who fought to resume power after Petropolis lost the title of capital to the city of Niterói. The political conflicts and the constant tension were present in the pages of the paper in its first years of circulation. The effort to rescue a Golden Age and attempts to turn Petropolis into capital again reflected the interests and power behind ink and paper. The study developed from bibliographical research on the historical-political context to exploratory research on the copies of Tribuna de Petrópolis located in the collection of the Historic Archives of Gabriela Mistral Municipal Library in Petrópolis, RJ.

Keywords:

History of regional media.. Tribuna de Petrópolis. Media and power.

\section{Pierde la capital para ganar un periódico: la creación de la Tribuna de Petrópolis y el rescate del poder simbólico y político regional}

\section{Resumen:}

Fundada en 1902 y en circulación hasta los días de hoy, la Tribuna de Petrópolis tiene más de un siglo de publicación en la ciudad de Petrópolis, RJ. A principios del siglo XX, el diario era un instrumento importante de (re) posicionamiento político del llamado Grupo de Petrópolis, políticos que luchaban por el rescate de poder después de la pérdida de la capital del estado a la ciudad de Niteroi. Los conflictos políticos y la constante tensión estaban presentes en las páginas de la Tribuna en sus primeros años de circulación. En sus páginas, el esfuerzo para una recuperación de una era de oro y los intentos de recuperar la capital refleja los intereses y poderes detrás de la tinta y del papel. El estudio se desarrolló a partir de la literatura en el contexto histórico y político y la investigación exploratoria en las copias de

\footnotetext{
${ }^{1}$ Uma versão preliminar do artigo foi apresentada no II Encontro Regional Sudeste de História da Mídia (2012), em Vila Velha, ES, e as discussões do evento foram incorporadas a esta versão publicada pela RBHM.

${ }^{2}$ Jornalista, Mestre em História, Política e Bens Culturais pelo CPDOC/FGV, doutoranda em Textualidades Midiáticas pelo Programa de Pós-graduação em Comunicação Social da UFMG. E-mail: ve.scosta@gmail.com.
} 
Tribuna de Petrópolis en la colección del Archivo Histórico de la Biblioteca Municipal Gabriela Mistral, en Petrópolis, RJ.

Palabras clave:

Historia de la media regional. Tribuna de Petrópolis. Media y poder.

\section{INTRODUÇÃO}

O território onde hoje se localiza a cidade de Petrópolis, antes conhecida como Fazenda do Córrego Seco, foi adquirido em 6 de fevereiro de 1830 por D. Pedro I, que pretendia construir ali seu palácio de verão. Residência particular que seria o destino da Família Imperial nos meses de calor que assolavam o Rio de Janeiro, era também local onde os filhos do Imperador poderiam se recuperar de doenças, graças ao clima ameno da serra.

Os planos de D. Pedro I foram abortados quando de sua abdicação, em 1831. Com sua morte, em setembro de 1834, a Fazenda foi destinada ao débito de dívidas acumuladas pelo Monarca. As questões do inventário só foram solucionadas em 1840, período em que o governo brasileiro pagou na justiça o valor da fazenda que, "simbolicamente, foi doada como presente da Nação Brasileira ao jovem Imperador por ocasião de sua Maioridade” (RABAÇO, 1985, p. 39).

A doação das terras colabora para a íntima relação de pertencimento que a cidade de Petrópolis mantém, desde sua fundação, com a Família Imperial e cuja aura simbólica permeia até os dias de hoje a vida cultural, econômica e política da cidade incluindo a imprensa local. Em especial, essa relação se faz presente na Tribuna de Petrópolis, periódico criado já na República, em 1902, para a defesa de um grupo político que se sentia prejudicado pelas decisões tomadas no âmbito estadual do Rio de Janeiro. Hoje, o GrupoTribuna é dirigido por um dos herdeiros da família imperial, Francisco de Orleans e Bragança ${ }^{3}$.

Este artigo se concentra nos primeiros anos de circulação da Tribuna, época em que a perda do status de capital do Estado do Rio de Janeiro para Niterói criou um desgaste político entre grupos republicanos. Com o fim da Monarquia, a publicação precisava se articular tanto em relação à imagem construída em torno da herança cultural e imperial da cidade, quanto em relação às demandas dos novos grupos no poder. Entre diversos jornais fundados na cidade na transição do século XIX para o XX, a Tribuna de Petrópolis é o único ainda editado, sendo o mais antigo em circulação. Sua

\footnotetext{
${ }^{3}$ Mais em: <http://mapadecultura.rj.gov.br/manchete/dom-francisco-de-orleans-e-braganca>. Acesso em 21 nov. 2016.
} 
trajetória reflete o desenvolvimento da cidade e resume seus principais acontecimentos, dando maior ou menor destaque a determinados grupos políticos e sociais ao longo dos anos.

Décadas antes da fundação do jornal, porém, a Fazenda Imperial de Petrópolis era o local onde a corte se protegia de possíveis invasões, das pestes ou de inimigos, e, claro, do calor do Rio de Janeiro. D. Pedro II realizou na construção de Petrópolis a idealização de um universo próprio, detalhadamente planejado para ser o local onde tudo deveria lembrar o Velho Continente. Assim, desde sua fundação, em 1843, Petrópolis conviveu com a necessidade de se fazer perceber como o local onde a realeza reencontrava suas raízes e representava seu poder e influência. Tudo deveria remeter à presença do Imperador.

Durante quarenta verões, nos meses de novembro a maio, a Cidade Imperial se tornou a capital do Império e se revestia da forte tendência aristocrática, levada por D. Pedro II serra acima. Para fazer da estadia da corte uma experiência plena, muito era investido na infraestrutura urbana. Não apenas a cidade nasceu do primeiro Plano Regional de Urbanismo do país, mas, desde seus primeiros anos, já apresentava jóquei clube, hipódromo, serviços de água e esgoto, iluminação a gás e ruas largas e arborizadas (ALMEIDA, 2005, p. 28). Não eram medidos esforços ou investimentos na manutenção do status, pois, “dentro da lógica de uma sociedade de corte [...] não há luxos nem desperdícios" (SCHWARCZ, 1998, p. 239).

De modo geral, a imprensa desenvolvida no Brasil a partir da segunda metade do século XIX espelhava a tranquilidade e a segurança transmitidas pelo Império no país (SODRÉ, 1966, p. 213). O panorama histórico do surgimento da imprensa em Petrópolis foi absolutamente favorável, graças à consolidação da comunicação e circulação de informações, pela proximidade da cidade com a capital, o Rio de Janeiro, e pelos fortes laços do Imperador com sua Petrópolis. A imprensa local rapidamente se beneficiou de algumas das mais importantes transformações da época.

Além disso, nos últimos anos do século XIX, Petrópolis vivia uma fase de prosperidade que também se registrava no quadro econômico da capital e de toda a região fluminense. A atividade cafeeira, que representava o setor mais dinâmico da economia nacional, era a principal fonte de recursos do Estado do Rio de Janeiro no período (ALMEIDA, 2005, p. 52) e as atividades industriais representavam também uma excelente fonte de insumos econômicos nos idos de 1880. O quadro industrial do 
período era promissor, com destaque para as indústrias têxteis em Petrópolis.

O quadro econômico favorável, somado à proximidade da cidade com a Família Imperial, delimitava o perfil do público leitor dos primeiros jornais da serra, ao mesmo tempo em que direcionava a imprensa local a se aproximar de temáticas mais abrangentes, que se expandiam para além dos limites geográficos de Petrópolis e davam conta de fornecer informações sobre os acontecimentos da capital e o desenrolar de decisões políticas. Assim, havia nos primeiros exemplares da imprensa petropolitana “uma preocupação em atrair leitores sofisticados e em conferir prestígio àqueles veículos e à cidade que os acolhia" (ALMEIDA, 2005, p. 56), pois "vivia-se em Petrópolis com os olhos voltados para o Rio, porém sob a proteção de uma aura de superioridade europeia que encobria a cidade e a mantinha resguardada" (ALMEIDA, 2005, p. 57).

Paralelamente aos avanços da imprensa local e ao desenvolvimento econômico, a partir da década de 1870 , começaram a surgir os primeiros sintomas da crise do Segundo Reinado, entre eles, o início do movimento republicano e os atritos do governo imperial com o Exército e a Igreja. Quando, em 1889, a campanha republicana já estava fortalecida no Brasil, D. Pedro II, já com a saúde fragilizada, exilou-se em Petrópolis com sua família. Na tomada de decisões que levou à queda do regime monárquico, Quintino Bocaiúva, figura importante para o jornal Tribuna de Petrópolis, conforme veremos a seguir, foi um dos que se uniu a figuras políticas como Rui Barbosa e Benjamin Constant para convencer o marechal Deodoro a liderar o movimento contra o Império (FAUSTO, 2002, p. 132).

Em 11 de novembro daquele ano, era em Petrópolis que o Imperador se encontrava antes de descer ao Rio de Janeiro para participar do Baile da Ilha Fiscal, que ficou conhecido como o símbolo do final da Monarquia no país (SCHWARCZ, 1998, p. 453-54). Ao retornar à serra, apenas quatro dias depois, o Imperador recebeu a notícia da formalização do regime republicano e do banimento da Família Imperial do país. Naquele 15 de novembro, foi instituído o governo provisório republicano, que contava com a liderança do Marechal Deodoro da Fonseca e de outras figuras políticas como o marechal Floriano Peixoto e os ministros Benjamin Constant, Quintino Bocaiúva, Rui Barbosa e Campos Sales, entre outros.

O jogo de capitais nos primeiros anos da República 
Conforme afirma Marieta de Moraes Ferreira (1994), a partir da Proclamação da República, as elites fluminenses passaram a enxergar no apogeu da cafeicultura uma "Idade do Ouro", criando uma mentalidade política que associava a conjuntura do café ao status e ao bom desempenho econômico do Rio de Janeiro. Entretanto, era inevitável que, com a República, a cidade e o estado se transformassem:

De principal polo econômico do país e mais forte base de apoio político da monarquia, o estado perdeu o status de "grande província imperial" com a implantação do regime republicano, inaugurando um longo período de dificuldades econômicas e políticas. (FERREIRA, 1994, p. 8).

Passava a ser necessário diferenciar os relacionamentos estabelecidos entre a capital federal e os governos estaduais, especialmente devido à fragilidade das ideias republicanas na cidade do Rio de Janeiro. Outra questão que colaborava para a problemática encontrada no Estado era a tendência à nacionalização que rondava a vida política no Rio, capital do Brasil. Isso porque, ao longo do período Monárquico, a cidade do Rio de Janeiro não desenvolveu uma mentalidade política voltada para os problemas regionais fluminenses, e grande parte dessa atitude se deve à "mentalidade cosmopolita" (FERREIRA, 1989, p. 21) assumida por suas lideranças políticas.

Testemunhava-se no interior do Estado uma movimentação ligada a dois grupos distintos, o Partido Republicano Fluminense (PRF), fundado em 1888, às vésperas da Proclamação, e o Partido Republicano do Estado do Rio de Janeiro (PRRJ), fundado em 1899. O PRF não se constituía como um partido forte e não agrupava os interesses dominantes de modo a solucionar os problemas do Estado. Já a fundação do PRRJ se deu quando Alberto Torres, já como presidente do Estado, em 1899, preferiu aliar-se a forças do norte fluminense ao invés de acirrar as disputas entre seu governo e aqueles grupos (FERREIRA, 1989, p.16).

Grupos concorrentes disputavam quem iria preencher o vazio de poder surgido com a queda da Monarquia, uma vez que "não havia partidos políticos em condições de exercer o papel unificador que até então coubera ao Imperador e à sua burocracia" (LEMOS, 1989, p. 44). O quadro de disputas pelo domínio político local estabeleceu-se, em 1889, com a nomeação, por decreto do presidente da República, de Francisco Portela, político de tradição campista (de Campos), para presidente do Estado do Rio.

O nome de Francisco Portela surgiu por indicação do novo ministro de Relações Exteriores, Quintino Bocaiúva, que deixou de fora José Tomás da Porciúncula, “talvez o 
republicano de mais sólidas bases políticas regionais, consolidadas durante vários mandatos que exercera como deputado provincial" (LEMOS, 1989, p. 45). Porciúncula tinha em Petrópolis uma de suas fortes bases políticas. Entretanto, a delegação federal para que Portela assumisse o cargo não garantiu o fim da disputa pela direção política:

\begin{abstract}
A disputa entre Portela e o Partido Republicano pela direção política do Estado chegou ao auge quando entraram em pauta as eleições dos deputados à Assembleia Nacional Constituinte, convocada desde dezembro de 1889 para reunir-se em 15 de novembro de 1890 . A legitimidade da República começava a construir-se com esse pleito, marcado para 15 de setembro de 1890 , e o desempenho eleitoral das facções políticas estaduais seria o principal indicador das perspectivas que estas poderiam começar a traçar em relação ao acesso ao poder. (LEMOS, 1989, p. 49).
\end{abstract}

Ao longo do processo da Constituinte, "Portela se desgastou profundamente, isolando-se das principais chefias políticas estaduais" (LEMOS, 1989, p. 53), mas manteve-se no cargo até 1891. Em 1892, o antes preterido José Tomás da Porciúncula foi eleito presidente do Estado do Rio de Janeiro. Além do desgaste com a Constituinte, a decisão de mudança da capital do Estado, de Niterói para outra cidade do interior, contribuiu para o isolamento político e a queda de Portela. Entre os diversos motivos apontados para a retirada da capital de Niterói, estavam "o alheamento da heterogênea população de Niterói [...] em relação aos interesses do Estado, sua submissão aos interesses da vizinha capital federal e a ameaça à autonomia do estado que essa proximidade representava" (FERREIRA, 1994, p. 106).

Embora fosse tema central nos debates políticos, a mudança da capital só se consolidou em 1893, com a eclosão da Revolta da Armada, que colocou Niterói sob forte ameaça. Foi graças a essa situação que Petrópolis recebeu, provisoriamente, a autorização para sediar as bases do governo como capital. Além de possuir as condições materiais necessárias para receber a estrutura de administração pública do Estado comércio, indústria e toda a herança cultural e social dos tempos do Império -, Petrópolis era também a base política de José Tomás da Porciúncula, à época, presidente do Estado.

Em 1894, a capital foi transferida para Petrópolis e lá permaneceu até 1903, quando Niterói passou a ser capital novamente, por imposição do recém-eleito presidente do Estado, Nilo Peçanha (FERREIRA, 1994, p. 107). Nesse meio tempo, principalmente a partir de 1897, o presidente do Estado, Alberto Torres (PRRJ), tinha o apoio de uma minoria situacionista e lutava contra uma maioria oposicionista que era 
fiel ao PRF. Os conflitos tornavam-se geograficamente localizados, e o grupo de apoio de Alberto Torres incluía o chamado "Grupo de Petrópolis", liderado por Hermogênio Silva.

A situação política mudaria com a candidatura de Quintino Bocaiúva para presidente do Estado, proposta por Nilo Peçanha ao presidente Campos Sales, em uma estratégia de "congraçamento político em torno de uma grande figura nacional" (LAMARÃO, 1989, p. 109). Bocaiúva havia se mantido alheio à cisão do PRF e era também uma das figuras mais importantes da imprensa republicana. Sua escolha para suceder a Alberto Torres no governo do Estado envolvia disputas políticas diretamente ligadas ao Grupo de Petrópolis, uma vez que Torres havia indicado Hermogênio Silva para seu sucessor:

Quintino Bocaiúva despontava como um candidato de conciliação, capaz de oferecer uma solução satisfatória à sucessão fluminense. $\mathrm{O}$ PRF divulgou oficialmente seu apoio à candidatura Quintino em $18 \mathrm{de}$ junho de 1900 [...]. Dois dias depois, a comissão executiva do PRRJ lançou manifesto indicando Quintino, o que implicou a retirada da candidatura de Hermogênio Silva. (LAMARÃO, 1989, p. 109).

Bocaiúva concorreu como candidato único e foi eleito presidente do Estado em dezembro de 1900, benefíciando o posicionamento político de seu articulador, Nilo Peçanha, na política fluminense. Foi um momento de grande prejuízo para o Grupo de Petrópolis, representado nas figuras derrotadas de Alberto Torres e Hermogênio Silva. O Estado do Rio de Janeiro apresentava uma situação econômico-financeira crítica em janeiro de 1901, quando Quintino Bocaiúva foi empossado, e esse quadro devia-se principalmente à acentuada queda dos preços do café. Além disso, o presidente do Estado teria que enfrentar "as feridas abertas pela recente luta partidária" (LAMARÃO, 1989, p. 117), que estavam longe de cicatrizar.

As discussões políticas após a posse de Bocaiúva passaram a girar em torno do retorno da capital para Niterói, conflito que cavou "uma profunda divisão na ALERJ", opondo grosso modo os seguidores de Hermogênio Silva e os de Nilo Peçanha" (LAMARÃO, 1989, p. 118), ou seja, o Grupo de Petrópolis e o Grupo de Campos. A vertente que era contra o retorno da capital para Niterói defendia os interesses do líder Hermogênio Silva, chefe político de Petrópolis e herdeiro de Alberto Torres, que fora eleito em novembro de 1900 o vereador mais votado da Câmara Municipal de Petrópolis.

\footnotetext{
${ }^{4}$ Assembleia Legislativa do Estado do Rio de Janeiro.
} 
Mas o movimento antimudancista perdia espaço para os partidários da mudança que, apoiados por Nilo Peçanha, aprovaram o retorno da capital para Niterói em lei promulgada em 4 de agosto de 1902:

O triunfo de posição mudancista no episódio da transferência da
capital contribuiu para clarear os contornos do quadro político
fluminense. Ao mesmo tempo em que o grupo Nilista se afirmava
como força hegemônica, a derrota de Hermogênio Silva lançava-o na
oposição e comprometia mais uma vez suas pretensões à presidência
do estado na sucessão de Quintino Bocaiúva. (LAMARÃO, 1898, p.
121).

Assim, Petrópolis viu-se envolvida em uma estratégia política de redefinição de poderes entre as elites fluminenses. Mas mesmo com a iminência da perda da capital, em 1902, a cidade era sinônimo de expansão, símbolo do desenvolvimento e da modernidade e assim buscava ser retratada a fim de manter o status político e social. A mudança definitiva de seu status ocorreu em junho de 1903, com a transferência do Poder Executivo para Niterói.

\section{Perde-se a capital, ganha-se um jornal}

Petrópolis passava, portanto, por um período de tensão social e política no início do século XX, pois perdia o status de capital do Estado. Por algum tempo, manteve todo o corpo diplomático e uma extensa cadeia de cultura e entretenimento, além das fábricas, indústrias e comércio de alto nível que atendiam a um público exclusivo. Foi em meio a essas transformações que, em 9 de outubro de 1902, surgiu a Tribuna de Petrópolis, primeiramente publicada às quintas e domingos e, em 1908, passando a ser o primeiro jornal local diário.

À frente da Tribuna estava a figura de Arthur Barbosa, considerado o pai da imprensa diária em Petrópolis. Sua carreira jornalística iniciou-se em outro periódico, a Gazeta de Petrópolis, ao lado de Martinho Morais, Hermogênio Silva e Artur de Sá Earp. Daí surgiram seus vínculos partidários com o Grupo de Petrópolis, que viria a defender nas páginas da Tribuna. Apesar de niteroiense, era a favor da permanência da capital do Estado na serra.

Em seus primeiros anos, a Tribuna de Petrópolis caracterizava-se por uma linha editorial preocupada em retratar questões como a dependência econômica do 
exclusivismo cafeeiro e os problemas enfrentados pelo município após a mudança da capital. Na edição comemorativa de seu centenário ${ }^{5}$, assim é retratado este período:

A situação deste período era angustiante. Em suas edições, o desafio 'Agonia nacional, para quem apelar?', eram farpas endereçadas aos políticos de então que trocavam gentilezas e favores ao administrador fluminense Quintino Bocaiúva. (SILVEIRA FILHO, 2002, p. 5).

A Tribuna parecia defender um ponto de vista diferente dos grupos que ainda se viam presos aos áureos tempos da expansão do mercado do café. Afirmava-se preocupada em retratar os problemas sociais e chamar atenção para o descaso que a cidade enfrentava naqueles anos. Nesse sentido, o editorial de apresentação do primeiro número do jornal, intitulado Nosso Objetivo, é bastante esclarecedor:

Só nos preocupa o interesse público. É assim que não nos cansaremos em pugnar pela prosperidade desta formosa e encantadora Petrópolis verdadeira joia deste torrão americano, que devia ser cuidada com todo carinho por todos os fluminenses, por todos os brasileiros. Infelizmente, parece, assim não vai sucedendo. (TRIBUNA DE PETRÓPOLIS, 9 out. 1902, p.1).

Destaca-se o descontentamento com a situação de abandono e descaso que a cidade enfrentava com a mudança da capital para Niterói. Em uma aproximação com o resgate do ideal da "Idade de Ouro", conforme apresentado por Ferreira (1994), o papel da Tribuna seria o de relembrar os tempos de glória da capital social e cultural do Império. O jornal assume a responsabilidade de defender a cidade, vítima do jogo político fluminense, e assim se refere à perda da capital para Niterói:

Inda há pouco dela arrancaram a capital do Estado - e já se pensa em privar do auxílio público alguns de seus úteis estabelecimentos de educação popular. Alimentamos, entretanto, a esperança de que este segundo ato não se realizará. Os nossos legisladores hão de refletir, e reconhecerão que não existe motivo para tamanha guerra a esta cidade - que não pesa sobre o Tesouro Estadual - por ser a mais bela, e mais asseada, e mais salubre de suas irmãs. (TRIBUNA DE PETRÓPOLIS, 9 out. 1902, p.1).

O caráter personalista da opinião política expressa no editorial aponta para os caminhos que seriam percorridos pelo jornal, cuja bandeira da oposição nas primeiras

\footnotetext{
${ }_{5}^{5}$ Quando da comemoração dos 100 anos do jornal, nos meses de outubro, novembro e dezembro de 2002 e janeiro de 2003, a Tribuna de Petrópolis lançou uma edição comemorativa em quatro fascículos colecionáveis, de 25 páginas cada, que recontavam sua história. A pesquisa do material foi assinada por Oazinguito Ferreira da Silveira Filho, historiador petropolitano responsável pela retrospectiva mundial, nacional, da história da imprensa petropolitana e da história da Tribuna de Petrópolis.
} 
edições é um marco forte de sua trajetória. O texto do editorial destaca, ainda, a preocupação em situar os problemas da cidade em um universo político maior:

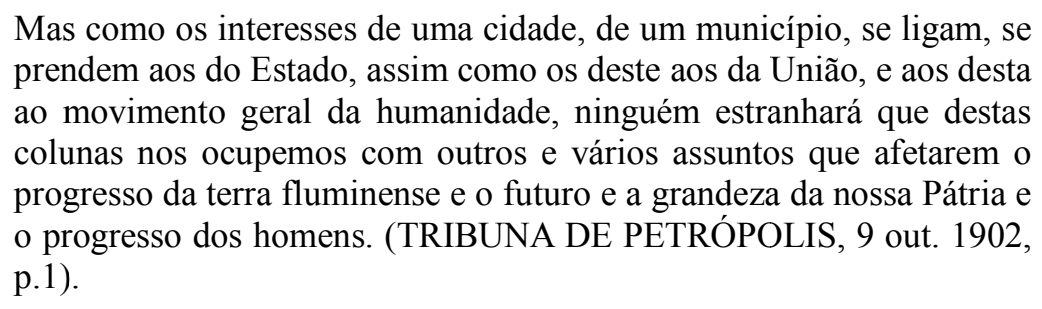

A Tribuna pretendia ser um jornal para falar em nome dos petropolitanos e colocá-los novamente no centro do debate político nacional, lutando contra as perdas sentidas em consequência da mudança da capital. Ao mesmo tempo, havia nela espaço para a realidade lúdica que a cidade ostentava no início do século $\mathrm{XX}$, aspecto que é constantemente destacado como uma vocação intrínseca, graças aos anseios do Imperador D. Pedro II:

\footnotetext{
A Tribuna não retratava somente os problemas de Petrópolis, registrava também divertimento e cultura. Era o encontro de profissionais e correspondentes da imprensa que formariam mais tarde o Círculo da Imprensa, era os saraus, bailes e eventos esportivos. (SILVEIRA FILHO, 2002, p. 5).
}

Assim, entre a missão de dar voz a um grupo político e a uma elite que acabavam de perder status e poder, a Tribuna nasceu também com o objetivo de resgatar a Petrópolis do Imperador, no sentido de registrar em suas páginas tudo o que de belo, lúdico e importante viria a acontecer na cidade naquele tempo. Os jornalistas assumiamse como porta-vozes da elite, "homens-memória com a missão de selecionar o que deveria ser lembrado, ressaltado, e de omitir o que se queria esquecido, em prol do bemestar público” (ALMEIDA, 2005, p. 58). E se Petrópolis perdia a chance de ser capital do Estado, ganhava um jornal cujos representantes estavam dispostos a se reerguer, se não pelo poder político, pelo poder simbólico atribuído a jornalistas e editores e a suas palavras, opiniões e representações de mundo registradas no papel.

\section{Cartas ao general Quintino: síntese de uma proposta política}

As primeiras edições da Tribuna continham textos escritos por Arthur Barbosa endereçados ao administrador fluminense Quintino Bocaiúva. Assinados por Carlos Ferraz, pseudônimo de Arthur Barbosa, acusavam diretamente a "falta de visão" do 
secretariado daquele chefe do executivo fluminense, (SILVEIRA FILHO, 2002, p. 5). A Carta ao General Quintino I, publicada em 23 de outubro de 1902, assim avaliava a relação de Bocaiúva com a política do Estado:

\begin{abstract}
Apoiado por todos os partidos existentes na terra fluminense, tendo ao vosso lado auxiliares de primeira ordem, a vossa obra seria imperecível, digna de todos os respeitos, se, em um dado momento, a politicagem não viesse tocá-la. A ambição de mando e de posições políticas foi o móvel único do que assistimos atualmente, com desprestígio para as instituições democratas, de que sois, pelo vosso passado, guarda fiel. (FERRAZ, 1902a, p. 1).
\end{abstract}

O papel conciliador e as tentativas de Bocaiúva de acalmar os ânimos políticos no Estado não pareciam satisfazer os ideais do Grupo de Petrópolis, e a Tribuna continuou a direcionar cartas de ataque ao seu governo por pelo menos outras cinco edições do jornal.

O periódico toma para a si a responsabilidade de se dirigir a Bocaiúva em nome de uma população que acabara de perder o prestígio de sediar a capital do Estado. $\mathrm{Na}$ Carta ao General Quintino III, o tema em debate é a resolução da Assembleia Legislativa visando à reforma da Administração Pública no Estado, assunto sobre o qual Carlos Ferraz tece os seguintes comentários:

No entanto, era nossa convicção que submetido ao vosso estudo o resolvido pela Assembleia, não lograria a reforma o concurso do Executivo para transformar-se em lei, servindo de razões do veto as reflexões expostas com sinceridade na Mensagem especial que acompanhou o projeto do Governo. [...] Ainda: Se não prevalecesse essa razão de ordem superior, havia outras que exigiam a repulsa do Executivo ao projeto. E, no entanto, nada vos demoveu, concorrendo tudo isto, que assistimos, para o desenvolvimento da descrença pública pelo sistema republicano, cada vez mais cavada e mais profunda em nosso Estado. (FERRAZ, 1902b, p. 2).

Publicada no sétimo número da Tribuna de Petrópolis, em 30 de outubro de 1902, a terceira Carta reflete uma profunda descrença com as decisões do responsável político do Estado e uma suposta esperança de tempos melhores que viriam para corrigir os erros do passado. Os apelos registrados nas cartas endereçadas a Quintino Bocaiúva eram, primordialmente, referentes aos interesses de um grupo desprivilegiado no embate político estadual. Infere-se daí que a importância da publicação das Cartas ao General Quintino fugia da exclusividade de reivindicações e identificações locais e buscava também debater os aspectos macro da política e da sociedade fluminense, reafirmando a 
postura do jornal na defesa do Grupo de Petrópolis, que buscava uma nova identidade simbólica de poder.

Essa postura foi possível porque, naquela época, "havia lugar para que um indivíduo, um jornalista, um político [...] utilizasse a mídia como instrumento declarado de ação política, para criar, a partir de seu prestígio e poder enquanto jornalista/político, o seu próprio jornal" (LATTMAN-WELTMAN, 1994, p. 119). Arthur Barbosa se utilizava do personagem Carlos Ferraz para falar em nome do Grupo de Petrópolis e o jornal foi conduzido em seus primeiros anos para esse fim.

Na Carta ao General Quintino V, publicada no número 9 da Tribuna, em 6 de novembro de 1902, a reforma constitucional que seria mais tarde implementada pelo sucessor de Quintino Bocaiúva, Nilo Peçanha, já era tema de insatisfação no jornal:

\begin{abstract}
A escolha do nome ilustre do Dr. João Rodrigues da Costa para exercer o cargo de Secretário Geral do Estado, quando o partidarismo indicava outros; [...] foi uma verdadeira surpresa para todos que acompanharam a elaboração da reforma. Entre os interesses do Estado e as vantagens pessoais inerentes à conservação de empregos, não hesitastes. (FERRAZ, 1902c, p. 1).
\end{abstract}

As Cartas ao General Quintino, muito mais do que colunas opinativas, configuraram-se como a síntese da proposta da Tribuna de Petrópolis no momento de sua fundação, refletindo a necessidade urgente de reposicionamento do grupo de oposição na política fluminense e a legitimação da voz da sociedade local. As Cartas não são opiniões inventadas para beneficiar o jornal, nem têm como objetivo apenas marcar sua postura política. Mais do que isso, refletem uma opinião coletiva adequada ao tratamento jornalístico do período, construindo um discurso mais consistente e representativo, ainda que passional.

\title{
Considerações finais
}

Acompanhando o desenrolar da vida política no Estado do Rio de Janeiro, o primeiro ano de circulação da Tribuna pode ser resumido como um período de forte atuação, no qual seus dirigentes e redatores, especialmente a figura de Arthur Barbosa, não mediram esforços para demonstrar sua insatisfação com o governo estadual e seu interesse de levar o Grupo de Petrópolis novamente ao poder. Na edição do aniversário de um ano do jornal, esse discurso é destacado como sua verdadeira vocação, motivo maior de sua existência: 
Traçado o nosso programa, temos procurado cumpri-lo com a maior religiosidade possível, em nome da causa sacrossanta que abraçamos e que foi a defesa do brio e da honra da terra fluminense, cujos legítimos interesses eram desprezados diariamente por um governo desorientado e sem escrúpulos de qualquer espécie. (TRIBUNA DE PETRÓPOLIS, 9 out. 1903, p.1).

Após um ano, a Tribuna já se consagrava como um jornal que falava em nome da sociedade local e defendia seus interesses como nenhum outro veículo havia feito anteriormente. Munida de um dever santificado autointitulado, a Tribuna era:

Como órgão de defesa dos mais sagrados interesses deste pedaço do torrão nacional, aviltado num período político, por um homem que mentiu ao seu passado de propagandista do regime proclamado em 15 de novembro de 1889! (TRIBUNA DE PETRÓPOLIS, 10 out. 1903, p.1).

É assim que a trajetória da Tribuna em seu primeiro ano de existência se confunde com os posicionamentos políticos assumidos por seu diretor, Arthur Barbosa, especialmente sobre os interesses dos grupos políticos locais que haviam sofrido com a administração estadual. O jornal cumpriu com o papel de enfrentar a autoridade máxima do governo estadual de frente. Nos anos seguintes, a relação de Barbosa com seu jornal era tão íntima que chegou a ser claramente descrita pelo jornalista Álvaro Machado:

Exultante de contentamento deve estar hoje Arthur Barbosa, o valente palinuro da Tribuna, contemplando esse ano decorrido - ano todo de trabalho constante, mas que assinala diversas vitórias alcançadas nos combates do pensamento em que Arthur Barbosa já está habituado a vencer, tal o vigor de sua inteligência, os recursos e a lógica do seu másculo talento. (MACHADO, 1907, p. 1).

Tomando para si a responsabilidade de defender os interesses locais, Arthur Barbosa não mediu esforços para tornar a Tribuna um veículo diário. Barbosa foi o grande responsável pelo sucesso editorial da Tribuna, pois "conseguiu consolidar a folha diária, enraizá-la na comunidade" (SILVEIRA FILHO, 2002, p. 8).

Ao completar seis anos em circulação e tornar-se um veículo diário em 1908, parece interessante à Tribuna assumir, ao mesmo tempo, uma postura defensiva e acuada no campo da batalha política, talvez prevendo a futura saída de Hermogênio Silva do poder, em 1910 - logo ele, que, apoiador da folha, teve um papel importante em sua manutenção. Há também uma confiança institucional estabelecida que permite ao jornal relacionar seus feitos ao bom desenvolvimento da cidade naqueles anos: 
E quem quiser dar-se o trabalho de pesquisar os benefícios e melhoramentos obtidos pela cidade, nestes últimos anos, há de certificar-se que todos eles se acham ligados a esta folha, que os reclamou, que os aplaudiu, em defesa única dos interesses do povo petropolitano. (TRIBUNA DE PETRÓPOLIS, 9 out. 1908, p. 2).

Tendo em vista o posicionamento declarado de Arthur Barbosa diante da realidade política fluminense, há de se ressaltar que a defesa dos interesses do povo petropolitano reforça a identidade do jornal como porta-voz da sociedade. A Tribuna de Petrópolis reivindica para si o ônus e o bônus do enfrentamento político simbólico que se deu naquele embrião de veículo de imprensa surgido em 1902.

Na sua fundação, a Tribuna de Petrópolis cumpriu um papel estratégico de posicionamento para um grupo político que também representava a voz de um partido. Essa força política pode não ter perdurado pelos anos seguintes, mas, certamente, determinou o perfil inicial da folha e garantiu que ela superasse os enfrentamentos políticos que sofria, graças a sua postura ofensiva. Após essa bem-sucedida primeira fase, a Tribuna de Petrópolis perdeu o fôlego inicial, passando a enfrentar dificuldades financeiras para sua sobrevivência, em um mercado que se profissionalizava rapidamente e se tornava cada vez mais capitalista.

Munidos da arma simbólica da imprensa, Arthur Barbosa e seu grupo de apoiadores políticos buscavam, declaradamente, lutar contra a perda de posições, status e valores da sociedade petropolitana. Não só a cidade havia perdido esse status, mas também muitos indivíduos já não dispunham dos benefícios de outrora. No ano de 1910, depois da saída de Hermogênio Silva da administração municipal, a existência da Tribuna foi posta em xeque pela primeira vez. O jornal estava intimamente relacionado com o apoio oficial de membros de partidos e autoridades políticas, e a saída de Hermogênio Silva mexeu com as estruturas financeiras do veículo.

Sua identidade de resistência, caracterizada pelas intenções políticas do Grupo de Petrópolis, passou a dar lugar à reconstrução de um imaginário imperial para a cidade, a fim de trazer de volta a glória dos tempos de D. Pedro II para a serra fluminense, análise que extrapola o escopo deste artigo. O surgimento da Tribuna de Petrópolis teve, portanto, o objetivo de dar voz a uma elite esquecida na serra, que passava a ver as decisões sobre o Estado e até mesmo sobre o destino do país serem tomadas sem seu consenso. Veículo político por excelência, a Tribuna buscava 
mobilizar a opinião pública, na esperança de que essas reivindicações trouxessem de volta a glória perdida junto com o título de capital.

Submetido em: 21.11.2016

Aceito em: 13.04.2017

\section{REFERÊNCIA BIBLIOGRÁFICA}

ALMEIDA, Cristiane D'Avila Lyra. Fantasia na Serra:representações de Petrópolis na mídia impressa. 2005.120 f. Dissertação (Programa de Pós-Graduação em Comunicação Social) - Departamento de Comunicação Social, Pontifícia Universidade Católica do Rio de Janeiro, Rio de Janeiro, 2005.

FAUSTO, Boris. História concisa do Brasil. São Paulo: Edusp, 2002.

FERRAZ, Carlos. Cartas ao general Quintino I. Tribuna de Petrópolis, Petrópolis, ano 1, n. 5 , p. 1,23 out. 1902 a.

. Cartas ao general Quintino III. Tribuna de Petrópolis, Petrópolis, ano 1, n. 7, p. 2, 30 out. 1902 b.

. Cartas ao general Quintino V. Tribuna de Petrópolis, Petrópolis, ano 1, n. 9, p. 1,06 nov. $1902 \mathrm{c}$.

FERREIRA, Marieta de Moraes. Em busca da idade do ouro.As elites políticas fluminenses na Primeira República (1889-1930). Rio de Janeiro: Tempo Brasileiro; Ed. UFRJ, 1994.

FERREIRA, Marieta de Moraes (Coord.) et al.. A República na velha província:oligarquias e crise no Estado do Rio de Janeiro (1889-1930). Rio de Janeiro: Rio Fundo, 1989.

LAMARÃO, Sérgio T. M. A cisão do PRF e a formação do PRRJ. In: FERREIRA, Marieta de Moraes (Coord.) et al. A República na velha província:oligarquias e crise no Estado do Rio de Janeiro (1889-1930). Rio de Janeiro: Rio Fundo, 1989, p. 97-115.

LATTMAN-WELTMAN, Fernando. Imprensa e sociedade: a economia do discurso público. ARCHÈ, Rio de Janeiro, ano III, n. 8, p. 117-133, 1994.

LEMOS, Luis do Couto Neto e. Francisco Portela, o governador de Deodoro. In: FERREIRA, Marieta de Moraes (Coord.) et al. A República na velha província:oligarquias e crise no Estado do Rio de Janeiro (1889-1930). Rio de Janeiro: Rio Fundo, 1989, p. 43-67. 
MACHADO, Álvaro. Parabéns. Tribuna de Petrópolis, mais um ano. Petrópolis, p. 1, 10 out. 1907.

RABAÇO, Henrique José. História de Petrópolis: antecedentes históricos e a povoação. Petrópolis: Instituto Histórico de Petrópolis, 1985.

SCHWARCZ, Lilia Moritz. As barbas do Imperador.D. Pedro II, um monarca nos trópicos.

São Paulo: Cia das Letras, 1998.

SILVEIRA FILHO, Oazinguito Ferreira da. A Tribuna nasce e tem como marco a preocupação social. Tribuna de Petrópolis, 100 anos em revista.Petrópolis, out. 2002. Fascículo I, p. 4-10.

SODRÉ, Nelson Werneck. A história da imprensa no Brasil. Rio de Janeiro: Civilização Brasileira, 1966.

TRIBUNA DE PETRÓPOLIS. O nosso objetivo. Petrópolis, p. 1, 9 out. 1902.

TRIBUNA DE PETRÓPOLIS. Seis annos.Petrópolis, p. 2, 9 out. 1908.

TRIBUNA DE PETRÓPOLIS. Um ano.Petrópolis, p. 1, 10 out. 1903. 